\section{CITIES AND REGIONS}

\section{IN COMPETITION? NEGOTIATIONS \\ FOR THE 2014-2020 PROGRAMMING PERIOD IN THE CZECH REPUBLIC}

\section{Vratislav HAVLÍK \\ Petra KUCHYŇKOVÁ}

\author{
Vratislav HAVLÍK \\ Assistant professor, PhD, Department of International \\ Relations and European Studies, Faculty of Social Sciences, \\ Masaryk University, Brno, The Czech Republic \\ Tel.: 0042-549-496.267 \\ E-mail:vhavlik@fss.muni.cz
}

\section{Petra KUCHYŇKOVÁ}

Assistant professor, PhD, Department of International

Relations and European Studies, Faculty of Social Sciences, Masaryk University, Brno, The Czech Republic

Tel.: 0042-549-494.863

E-mail: p.kuchynkova@gmail.com

* This article has been written as part of the research project 'Europe 2020: A Horizon of Change of Relevant Actors of the Czech Republic's Political System' (Czech Science Foundation project GA13-24657S).

\section{Abstract}

Over the past two decades, the concept of multi-level governance (MLG) has been increasingly discussed by scholars in the field of European integration. While Gary Marks wrote about a four-level arrangement (supranational, national, regional, and local), over time the regional and local levels often became lumped together as 'substate actors' and so easily conceptually interchangeable. This text, however, shows the fallaciousness of this reasoning. In certain circumstances we can find a competitive relationship between cities and regions, positioning themselves against each other for resources and access to national and supranational fora, especially in the context of the new regionalism. The cities have been given substantial support from the European Commission in recent years and we argue that this new constellation may have a remarkable influence on relations and possibly also lead to conflicts among local and regional actors in EU multi-level governance. This was possible to be clearly seen in the Czech Republic (CR) between 2012 and 2014, when heated negotiations took place regarding the implementation of the Integrated Territorial Investment (ITI), a financial instrument of EU Cohesion Policy which was implemented on the substate level -i.e., in cities and regions. In the CR this competition took place in a specific context, which also influenced its outcome.

Keywords: new regionalism, multi-level governance, governance, substate actors. 


\section{Introduction}

One certain flaw or problem of the concept of multi-level governance (MLG) is that as the use of the concept increases, the formulation of different expressions and definitions increases accordingly. This situation can be observed even in defining the level on which governance occurs. While Gary Marks (1993, p. 392) spoke at the outset about four levels of governance - European, national, regional, and local - subsequent authors often connected the two latter levels under the collective term 'subnational' or 'substate', which has been very misleading at the least. The use of the expression 'substate' can, in some specific cases, create the impression that there exists a coherent group of actors (comp. Callanan and Tatham, 2014) with more or less similar interests and behavior, which is not necessarily the case. This 'substate' term derives from the three-level concept of policymaking. Kassim (2005) uses this approach when discussing the Europeanization of substate authorities, which he defines as subnational states, regions, and municipalities (similarly to Jeffery, 2000). The fact that local arena is described relatively haphazardly in definitions of MLG is rather alarming, as it obscures the clarity of the concept. The answer why this happens exists. As research on Czech and German cities shows (Havlík, 2013), it is not possible to speak of 'typical' actors in MLG in the case of cities, because the nature of their actions is quite heterogeneous. This statement was valid around 2010, and is more or less valid still today, even though the role of major cities (with metropolitan suburbs) has changed since that time. The role of major cities (typically those with more than about 100,000 inhabitants) as clearly emancipated actors emerged decisively after 2007 (and more strongly after 2014) based on the new period of the EU regional policy, which following the Lisbon strategy provided them with much stronger tools in implementing the EU structural funds (the so-called 'territorial dimension', see below). The idea behind this was to raise competitiveness across the EU by making 'new internationally significant territories of economic dynamism' (Deas and Lord, 2006, pp. 1848-1849). This empowering of cities, above all the empowering of the so-called 'urban regions' or 'metropolitan' areas, has been often discussed in previous literature on 'new regionalism' (Harrison, 2007; Deas and Lord, 2006; Zimmermann and Heinelt, 2012; Zimmermann, 2008; Bafarasat, 2016, etc.).

This text's ambition is therefore to offer a new perspective on the relations between substate actors; more specifically, the text shows that in certain circumstances we can find a competitive relationship between cities and regions. It was possible to clearly see this in the Czech Republic between 2012 and 2014, when heated negotiations took place regarding the implementation of the Integrated Territorial Investment (ITI), a financial instrument of EU Cohesion Policy which is implemented on the substate level - i.e., in cities, metropolitan areas, and regions.

This new instrument is interesting for a variety of reasons (see below), but particularly because it confirms the above-mentioned attempts of the European Commission to broaden the implementation of cohesion policy, implementing it not only region- 
ally, but also to metropolitan (subregional and local) areas (comp. Zimmermann and Heinelt, 2012). This presents a challenge to current understandings of the concept of multi-level governance from the point of view of the division of individual levels of governance. In other words, it is necessary to address possible changes in the roles of substate actors, which were brought about in the context of the new forms of EU Regional Policy during the 2014-2020 programming period. Speaking about metropolitan governance is of course 'nothing new', but it may be worthwhile to update this discussion, since cities have been given substantial support from the European Commission in recent years. We argue that this new constellation may have a remarkable influence on relations and possibly also lead to conflicts among local and regional actors in EU multi-level governance.

In light of this, the Czech Republic is a prime case for study. First, as one of the new Member States of the EU, it is a major recipient of financial support under the cohesion policy. It is precisely due to the fact that substate actors have a tangible chance to acquire a substantial amount of money from the structural funds that they have more than sufficient reasons to fight for this money. The structure of the Czech state also makes it a good fit for research. As a unitary state, the regional level did not play a significant role before entry into the EU, and therefore regions had a similar initial position to cities during the EU accession. As a part of the post-communist heritage, cities lacked a history of any real autonomy and the regions were newly formed in the 1990s after a decade of internal political disputes about their formation, number, and competencies. Both cities and regions had to adapt to specific mechanisms of both direct and indirect communication with EU actors and interest promotion bodies. Moreover, this adaptation has been further complicated by problems of a heritage of political and administrative culture shared by various post-communist 'new' EU member states. The interaction of all these circumstances, combined with the amount of European money that cities and regions compete over, make the Czech Republic an interesting object of research.

In the next parts of the text, we are going to present step by step the features of Czech substate governance and the relations between regions and cities. In the second section, we put our case study in the context of the new regionalism theory and show that the changes of the substate landscape and of the relations between cities and regions are undoubtedly driven by the activities of the EU Commission. In the third section, we present the specifics of the Czech cohesion policy and discuss the influence of these specifics on the performance of Czech substate actors in the EU multi-level governance. Then, after explaining our methodology we present in the fifth section our findings. First of all, we present the discussion about the implementation of the ITI financial tool, than we present and explain the ways which cities and regions used for their interest articulation. Finally, we show that the ITI tool was a crucial and divisive factor for the relations of cities and regions in the context of particular problematic factors concerning the Czech Republic. 


\section{Subnational actors and their strategies \\ of interest articulation in the context of MLG}

Subnational actors have a wide range of options in the process of interest articulation in the context of multi-level governance of the EU. For greater clarity, these options can be positioned within various existing concepts (MLG, Europeanization, paradiplomacy, the partnership principle, etc.) which, rather than identifying the points that cities and regions can use, offer a basis to understand the activities of these actors. In this text, however, it functions as a departure point for formulating the argument that cities may be seen as being on equal footing with and, in some cases, even competitors to regions.

Activities of substate actors can be further divided as domestically- and foreign-oriented on the basis of existing empirical studies (comp. Münch, 2006, etc.). In the case of domestic activities, this is above all interaction with the relevant government ministry, either directly on a bilateral basis, or more commonly in the form of membership in an organization representing the interests of such actors (association of regions, organizations of towns and cities). In their 'paradiplomacy' (Soldatos and Michelmann, 1992), substate actors see increasing regionalization as a 'throwing down of the gauntlet' to increase their activities and attempts to influence the content of European legislation. In this process, various possible entry points exist; just as in the case of interest articulation on the state level, these can be approached bilaterally (direct contact to EU institutions, participation in public consultations, etc.) as well as multilaterally (membership in the Committee of Regions, CEMR, Eurocities, etc.).

The term 'strategy', used in the title of this section, is imprecise and often distorted. As previous research (Havlík, 2013) shows, while some substate actors have a detailed and elaborate approach to 'European' interest advocacy, ${ }^{1}$ others hardly have any 'strategy' at all. In this context, it is interesting that the main line dividing successful from unsuccessful substate actors is neither the structure of the executive branch in a given state (unitary vs. federal), nor the 'dichotomy' between old and new EU Member States, nor higher or lower levels of corporatism in a given state. Often, success of a specific substate actor is determined by how proactive it is in its approach, and by its own decision to actively campaign for its interests regarding individual European policies (comp. Callanan and Tatham, 2014).

This finding is important for further argumentation. It is clear that while initial conditions for individual substate actors vary (some are larger, wealthier, and undoubtedly more influential), each of these actors have at least a few options to articulate their interests. Moreover, MLG rejects presenting cities as actors positioned vertically below regions, but instead places them in a circle beside regions; this reveals their options in a completely different light than they would be in a more 'conserva-

1 Here, we understand the term 'European interests' as specific interests of substate actors in relation to the decision-making process of the European Union. 
tive', linear understanding. However, cities did not always have the same opportunities in MLG as regions. Their placement on the same level as regions in MLG is accurate, but, from a quantitative point of view, they were in charge of a smaller amount of money in recent decades. The concept of 'new internationally significant territories of economic dynamism' (Deas and Lord, 2006, pp. 1848-1849), as mentioned above in speaking about the new regionalism, changed their opportunities and possibly their position in MLG as well. Although the European Commission does not give the cities the right to implement the ITI directly, they do have the opportunity to enter into competition (with other regional or subregional actors) with a serious chance to win. In other words, the EU Commission's latest trend in making regional policy has been to establish incentive structures for regional and subregional actors in order to let the best win, but without directly saying who the best is and who exactly the implementing authority should be.

In this text, we argue that as long as cities did not get any real opportunity to decide about the implementation of a substantial part of structural funds on their own, their participation in MLG seemed rather formal and fit for rather theoretical disputations of political scientists. But in the context of the gradually developing new regionalism, we may speak during the last decade about cities as 'true actors' of MLG, as they have been strongly supported by the European Commission (comp. Zimmermann, 2008). We further argue that this granting of support may give rise to tensions between regions and cities, which makes further research of their relationship in this field welcomed (comp. Deas and Lord, 2006, p. 1862).

Since 2006, when Deas and Lord wrote that there is 'little or no evidence of significant conflict' of 'new regions' with 'old regions', the respective literature has become more profound (Deas and Lord, 2006; Zimmermann and Heinelt, 2012; Bafarasat, 2016). In spite of this, case studies about the conflict of new and old regions in the EU money distribution process are still lacking. The goal of a specific case study in the context of the Czech Republic is thus to examine the relationships between regions and cities in detail, particularly in a country in which regions as actors have not been historically more influential than cities. This makes it an ideal and interesting area for research.

\section{Development of cohesion policy in the Czech Republic}

For Czechoslovakia and later for the Czech Republic (CR), the year 1989 signified a historic break not only in the sense of the end of single-party rule and the transition to democracy, but also slowly facilitated the debate on the style of governance. Regionalization and the development of regional policy were not excluded from this debate, addressing the goal of reducing regional disparities. However, in the first half of the 1990s, this newly formed goal was not visibly achieved. To a large extent, actual work toward it was connected to the Czech Republic's drawing nearer to the EU in the second half of the 1990s, as a functioning regional administrative organ was one of the conditions for entry (Dočkal and Kozlová, 2006). Thus in the CR, regionalization often has correlated with increasing Europeanization. On 1 January 1996, the 
Ministry of Regional Development was established, and in the following year a constitutional amendment was passed to create and implement 14 administrative units known as 'kraje', in the year 2000.

A similar regional division of the country had existed in the communist era as well, but in light of the centralized character of state administration, the kraje had rather formal powers and competences than a real power. In addition to this, the new structure and number of regions does not copy the structure from the communist era: some new regions were established, and some of the previous regions were divided into smaller units. This means that both regions which had some tradition of existence as 'kraje' even during the communist era and some regions, which were newly established in the 1990's, exist. Also it quickly became clear that the attempts of the CR to create a situation in which the kraje would be recognized as NUTS II regions would be generally unsuccessful, ${ }^{2}$ and in an effort to secure money from the structural funds, some of the kraje were merged for NUTS II purposes; this resulted in units that were even more artificial, lacking any homogenous identity or historical borders (comp. Heinelt and Lang, 2011; Dočkal and Kozlová, 2006; Benedek and Bajtalan, 2015). This is not to say that the kraje at the time of their creation had a natural position or authority - they did not. The law on kraje (Zákon o krajích č.129/2000) indeed gave them relatively limited powers; with the exception of the right to propose laws in the Parliament, these were certain limited powers in transportation, education, and health-care. ${ }^{3}$

Cities had in that time certain amount of experience with interest articulation, which they had gained at the beginning of the $20^{\text {th }}$ century (in Austria-Hungary) when they began to form associations. In the modern era, cities renewed their associative actions shortly after the Velvet Revolution as the 'Union of Towns and Municipalities of the CR' (Svaz měst a obcí ČR, UTMCR) and shortly thereafter were seen as a traditional partner of the government. The kraje had to form a similar structure from scratch. The Association of Regions of the Czech Republic (Asociace kraju ČR) became a respected and active partner of the government relatively quickly, in part due to the low number of kraje; the association thus was able to more easily aggregate the positions of its members than the UTMCR.

But even at the most general level, it cannot be stated that the kraje were a priori more influential actors, more likely to succeed in their attempts to lobby for their interests than cities were. In particular, large statutory cities did not face the same obstacles as smaller cities - above all, a lack of population, which implies an unattractive position for industrial development and employment and a generally lower 'pull' in negotiations with central organs of the state. Brno and Ostrava, the second and third

2 This finding is not without exceptions. Prague, Central Bohemia, and Moravia-Silesia are at once kraje and NUTS II regions, though another five NUTS II regions are composed of two or more kraje.

3 This act is formulated as the right to form a public-benefit corporation, including such entities as some hospitals and schools. 
largest cities in the Czech Republic, certainly did not experience these obstacles and to a large extent represented equal partners to their regional counterparts. ${ }^{4}$

Among other things, the position of kraje and cities is connected to how the EU structural funds were implemented in the CR. The means by which the Czech Republic set up its operational programs for securing of monies from the structural funds has always been a subject of discussion, particularly concerning the degree of decentralization of the implementation structure. The country's first period of regional policy was brief, from the date of its entry into the EU (May 2004) to 2006. Individual NUTS II regions did not have access to their own operational programs, but drew funds from a common program, the Joint Regional Operational Program (Společný regionální operační program, JROP). Conversely, during 2007-2013 seven regional operational programs (ROPs) appeared in addition to the nationwide thematic operational programs, indicative of the clear decentralization of the entire process of European subsidy acquisition. However, the process of implementation of European regional policy was at this time accompanied by widely publicized corruption scandals that embroiled many NUTS II regions. Although these cases of corruption were officially linked to some NUTS II regions, there always have been connotations to the politicians of kraje, since the kraje are a constitutive part of NUTS II regions and in some cases (see above), a kraj has the same territory as the NUTS II region. Partly in response to these scandals, regional programs for the 2014-2020 period were canceled and the country shifted back to centralization of the whole process under the JROP heading.

However, the kraje 'lost' in their battle over the implementation of another powerful tool. So-called 'Integrated Territorial Investment', which (like the original ROP) was conceived of as a similar decentralized instrument, was awarded to major cities after a protracted fight. Precisely this process of the rise of competition between kraje and big cities is the topic of the following portion of the text.

\section{Research design}

In connection with the theoretical and empirical findings described above, this article attempts to answer the following research questions:

1. Which strategies, approaches, and mechanisms did the given substate actors (kraje and relevant cities ${ }^{5}$ ) use to advocate for their interests in the area of im-

4 One vivid (though somewhat misleading) illustration of this is the information on the financial income of cities and kraje. While the kraj of South Moravia had an annual income of over CZK 5 billion, just by itself the city of Brno (the kraj's capital) received almost double (see Brno's annual budget, South Moravia's annual budget). This information is obviously mentioned only for illustrative purposes. This does not factor in the fact that part of this budget is non-discretionary and earmarked for various reasons (social services, transit, etc.) and the amount is also dependent on the actors' other investments according to their own considerations.

5 In this case, relevant cities are those cities which are components of the seven metropolitan areas in the Czech Republic qualifying for ITI implementation. Towns located in five of these seven areas volunteered to participate in this research. 
plementation of the EU's regional policy tools in the case of negotiations on ITI implementation, and how does this occur on the domestic as well as on the international/EU levels? And why?

2. What were the reasons for the conflict between the old and new regions (kraje and major cities) in the Czech Republic and which main factors influenced the outcome of the conflict?

These research questions help us to discover specific differences in the tactics of the relevant cities in the CR on the one hand, and kraje on the other, and at the same time help in directing attention to important factors which influence these differences in approach, both in the case of cities as well as in the case of kraje.

First off, regarding cities, it is logical to study the cities of the seven largest metropolitan areas in the CR as actors qualified to use the ITI mechanism (districts of ÚstíChomutov, Plzeň, Prague, Hradec Králové-Pardubice, Brno, Olomouc, and Ostrava). Of these, the main cities of five of the districts agreed to participate in the research project (Prague, Plzeň, Brno, Olomouc, and Ostrava). ${ }^{6}$ This group of major cities in their corresponding metropolitan areas represents a sufficiently representative sample. In the case of the kraje, out of a total of 14, five took part in the survey (more than one-third, and thus they represent an appropriate sample): The Capital City of Prague, Moravia-Silesia, and South Moravia are three of the top four most-populated kraje in the CR (each with over 1 million residents), while the Hradec Králové Region and the Karlovarský (Carlsbad) Region are less populated (the Karlovarský Region is the least populated of all 14). The sample demonstrates the diverse character of the individual kraje, not only from a demographic, but also from a geographic point of view. Moreover, the sample takes into account varying structures of population distribution. For example, South Moravia has one dominant city (Brno) in terms of population and economic potential, which makes it a magnet for commuters, etc. In contrast, in Moravia-Silesia there is a larger number of cities that have grown into a large agglomeration. Because such characteristics may have a significant impact on methods of interest articulation, they are critical to the selection of an appropriate sample. One specific case included in the research is the Capital City of Prague, which is at once a major city and a de jure kraj, as well as the capital. This gives it a unique position in terms of socio-economic characteristics, as well as in bargaining processes, both in national and in the EU-level structures.

Methodologically, this research employs semi-structured qualitative interviews, or more precisely 'expert interviews' (Littig, 2009). This technique was chosen in light of the goals of the research, which were focused on the practical utilization of existing mechanisms at the national as well as at the European Union level, on what

6 According to the Czech Statistical Office, Prague, Plzeň, Brno, Olomouc, and Ostrava are classified as 'Velkoměsta' or 'Major Cities', which have more than 100,000 residents and are the largest cities in their respective metropolitan area; their relevance for research is the strength of their negotiating position as representatives of a given metropolitan area. 
specific negotiation and communication practices occur through a given channel, and what factors influence these approaches. ${ }^{7}$ Interviews were undertaken with employees of city halls as well as offices of the kraje..$^{8}$ Emphasis was placed on the selection of employees in departments which were directly concerned with regional or local development, structural funds, and occasional employees who had the authority to communicate with appropriate actors at the national or EU level in the context of interest articulation of the city/kraj on these levels (typically in the Office of the Mayor or the Office of the Hejtman ${ }^{9}$ ). Other respondents (who functioned as a control group) included employees of corresponding structures at the national level that articulate and aggregate interests of cities and kraje; these structures have means of communicating their interests to appropriate government authorities (typically the executive branch, and especially the Ministry for Regional Development), and in some cases to structures at the supranational level (EU institutions). In the case of cities, this meant the aforementioned Union of Towns and Municipalities of the CR (UTMCR); in the case of the kraje, the Association of Regions of the Czech Republic (ARCR). Cities and kraje can also communicate directly with ministries, so employees of the Czech Ministry for Regional Development were also included among respondents. Due to their professional focus, background and experience, some of the respondents had useful things to say also regarding the relevant structures on the EU level (CEMR, the Committee of the Regions, the European Parliament).

Altogether, 16 personal and one telephone interview took place. Information gleaned from these semi-structured interviews was supplemented by follow-up emails when necessary. Interviews (data collection) took place in the period between May 2014 and March 2015, thus in a period in which the circumstances that the individual respondents experienced regarding preparation and implementation of ITI were still fresh in their memory. By respondent request, all interviews have been anonymized.

The Czech case is not only interesting due to the aforementioned implementation of this new tool for territorial development in a de facto unitary state (with a tradition of local autonomy that was interrupted during the $20^{\text {th }}$ century). Above all, the dis-

7 For the characteristics concerning both the appropriateness and also the limits of qualitative interviews as data collection method see e.g., Burnham et al. (2008) or Dexter (2006).

8 Some of the interviews were made as a part of broader research, which was focused on the activities of Czech cities and regions concerning the articulation and promotion of their interests in the process of the development and implementation of EU legislation. As the aims of the research were to provide feedback and recommendation for further activities in these fields, it was focused mainly on the persons who were directly responsible for the everyday execution of these tasks and activities, i.e., the responsible local and regional officials and the representatives of particular structures for articulation and aggregation of the local and regional interests - the Association of Towns and Municipalities of the Czech Republic and the Association of Regions of the CR.

9 The Hejtman is the elected leader of the kraj. 
continuity at the regional level makes this case important. Despite this, both types of actors - kraje as well as cities - have developed more than a few initiatives to capitalize on the implementation of ITI on 'their' level, either regionally or at the level of the agglomeration. Beside the parameters of ITI specified (somewhat vaguely) at the EU level, specific internal characteristics (such as territorial administrative structure, the positions of individual actors in the negotiating process, and the motivations of these actors) also affect how ITI is implemented in the CR.

\section{Empirical findings}

\subsection{A discussion on Czech ITI implementation}

Since about 2012, an intense discussion has taken place in the Czech Republic regarding the implementation of the 'Integrated Territorial Investment' program, one tool unveiled in the context of 'territorial and urban dimensions of cohesion policy $2014+$ '. The European Commission explained that 'economic and social cohesion cannot be achieved at the European level without a stronger focus on the territorial impact of EU policies' (European Commission, 2014, p. 2).

One problem since the very beginning has been the vague definition of the territorial units in which ITI is to be implemented. The basic conditions the Commission refers to are limited to stating that implementation should occur in 'a designated territory and an integrated territorial development strategy' (European Commission, 2014, p. 2). This was followed by another explanation, which also was not very precise:

'Any geographical area with particular territorial features can be the subject of an ITI, ranging from specific urban neighborhoods with multiple deprivations to the urban, metropolitan, urban-rural, sub-regional, or inter-regional levels. An ITI can also deliver integrated actions in detached geographical units with similar characteristics within a region (e.g., a network of small or medium-sized cities). It is not compulsory for an ITI to cover the whole territory of an administrative unit.' (European Commission, 2014, p. 2).

From the perspective of the European Commission, this is a relatively understandable step, as the territorial administration of Member States in the EU is varied enough that any more precise definition under which ITI might be implemented would be problematic. At first glance, it was not obvious whether future ITI implementation would be dealt with more at the regional or at the local level. Though clearly the majority of the definitions discuss various forms of subregional forms of territory, it is crucial to note that it is not 'compulsory' for an ITI to 'cover the whole territory of an administrative unit', though of course it implies that it theoretically could. From the perspective of the typology developed by Arthur Benz (2009, comp. Marks and Hooghe, 2005), ITI itself is evidence of the so-called 'functional federalism' of the EU, which is characterized by the formation of 'special-purpose jurisdictions'; in the case of ITI, subnational entities have a single goal: to implement ITI. The formation of specialized jurisdictions having only a single specific goal is a logical phenomenon, 
as many territories that have been formed by history and geography are ill-suited to fulfill the conditions needed for more modern undertakings, and it is thus necessary to create ad hoc territorial units. The effect of the Commission's relatively open design of ITI thus was a situation in which a wide variety of actors started to realize that they could implement ITI, and went about attempts to fully maximize these options.

In the Czech Republic, urban agglomerations and especially the kraje made attempts from the outset. In the period 2007-2013 the kraje had 'Regional Operational Programs (ROPs)' at their disposal; the media (and not only them), however, associated these with corruption scandals. Eventually, key players in some kraje were arrested, and EU regional policy became a shorthand for corruption in the eyes of the public (see Havlík, 2015). The government responded to these developments by deciding to scrap individual ROPs for 2014-2020 and form a single 'Joint Regional Operational Program (JROP)' which would centralize the management of regional policy and would (in the government's view) guard against possible continued corruption on the regional level. Thus at the start of the 2014-2020 round, kraje faced a situation in which a lucrative, financially secure, subsidized territorial instrument was clearly welcomed. Moreover, they were able to point out the fact that many other EU countries were considering ITI implementation exactly at the regional level (Romania, Spain, etc.), or in both regions and urban areas (Slovakia, Italy, Germany, etc.). For a long time, this argument seemed decisive (or at least the kraje were convinced).

Major cities, however, also made an argument that they, rather than peripheral areas (with reference to reducing regional disparities) should be supported as 'poles of growth' (see e.g., Zimmermann and Heinelt, 2012; Hradec Kralove, 2014); major cities along with their agglomerations had the potential to be engines of economic growth and job creation. It was this point that substantially divided the arguments of the kraje and the cities, and created short-term, mutually antagonistic postures.

\subsection{Divided strategies of Czech kraje and cities in the process of interest articulation}

Options and strategies of cities and kraje in the CR often differ in the interest-articulation process. By definition, one reason for this is that kraje are geographically and demographically larger and thus have a logically greater chance of being 'heard'. In the context of EU regional policy implementation, they have enjoyed a more advantageous position than cities in the last decade. They have been administrators of ROPs (some of them de jure, the others de facto, see above) and more frequently represented in key advisory bodies, including ROP monitoring committees, ministerial working groups, etc. In these same fora, cities have usually had only one or two representatives, the same position as NGOs. Kraje thus have been in a better position vis-à-vis cities from the point of view of access to information and options to present their interests.

Cities and kraje share some basic mechanisms when discussing interest articulation. Both types of actors have umbrella organizations whose goal is to aggregate the interests of their members, select a common position, and accordingly articulate it to 
other actors. In the case of EU regional policy, these 'other actors' are typically the government or respectively the relevant ministry; at the EU level, typically the Council of European Municipalities and Regions (CEMR), Eurocities (for major cities), the Committee of the Regions, the European Commission, etc. Both national umbrella organizations - the UTMCR and the ARCR - are fully professionalized and completely aware of the options they offer; their differences can be seen in (A) how they utilize their options, and (B) which communication channels they choose to articulate their interests.

In 2000, the government took the step of creating the kraje as substate units. However, the main motivation was not to counter any trend of centralization, but instead to prepare the country for EU membership; a functioning regional administration was one condition of membership (comp. Dočkal and Kozlová, 2006). This is important also from the point of view of the overall development of political and administrative culture in the Czech Republic, when we think about the position of substate (in this case regional) actors in the whole system of communication, policy making, and governance in the $\mathrm{CR}$ as a unitary state. Kraje thus from the beginning of their existence should be understood as new actors (in spite of the above-mentioned 'history' of communist kraje), who had to create their communication channels from scratch.

They never completely managed to emancipate themselves and present their interests on EU affairs except mainly through the central government, which they considered (and still in part consider) as their natural and closest partner in spite of their status as autonomous substate actors. The interviews indicate close communication on the part of the kraje with ministries and conversely their hesitation to establish or reestablish their representatives in Brussels. ${ }^{10}$ These kraje focus on articulating their interests through national-level access points, especially the ministerial level, which they also see as a natural partner for interest promotion at the EU level. ${ }^{11}$

This may be illustrated also by the fact that several Czech kraje terminated their direct representation in Brussels in recent years. The reasons were not only economic, but also personnel (difficulties to find proper staff with enough experience in working on various levels of governance, including not only regional or national, but also the EU level). These facts in combination with frequent fluctuation of this properly

10 Shortly after the EU accession, each kraj created a representative for the EU located at the 'Czech House' in Brussels. After a few years, however, the kraje began to close their representatives' offices. Of the five kraje under study, in 2015 only three still had an EU representative.

11 For example, in one interview, an employee of Moravia-Silesia clearly stated that when developing the kraj's position concerning the legislation affected by the EU or on the European level, it was primarily transmitted through a ministry. The relevant ministries are deemed the primary partner with whom the kraje communicate and they lead the debate in cases at the European Union level, such as the preparation of new legislation that directly affects the substate level (' $[t]$ he partner for the European Commission is understandably the state, individual departments.' Interview, Kraj Moravia-Silesia, 8 July 2014). 
trained and experienced staff represent certain negative elements of the administrative culture, which are not without impacts on the practice and effectiveness of the process of interest articulation on the supranational levels ('[i]t's all about who is sitting at the permanent representation in Brussels. If they're only there to be there, then it's meaningless.' Interview, Kraj Karlovarský, 10 September 2014). It is necessary to point out that the experience with permanent regional representation in Brussels varies in different Czech regions. Nevertheless, the kraje which do have an office in Brussels see it primarily as a figurehead position, as typically have one employee (and possibly a single intern), which is not sufficient to systematically promote the interests of the kraj in the EU; in addition, it makes this activity highly dependent on the personnel factor. ${ }^{12}$ Even 15 years after its founding, the Association of Regions of the $\mathrm{CR}$ has not yet established a common representation of the kraje in Brussels, though respondents of the Association indicated this is regularly considered (according to ARCR, a common representation of the kraje in Brussels would help unite capacities and end the current fragmented situation).

Cities had been represented in Brussels through the UTMCR since 2007, though this office was later closed. In this case, however, it was understandable. Oldřich Vlasák, the vice-chairman of the UTMCR, has been the executive president of the CEMR since 2002, and in 2012-2014 was a vice-president of the European Parliament. Interests of Czech cities therefore have been represented at a high level and any other advocacy was unnecessary in the UTMCR's view. ${ }^{13}$

A comparison of cities and kraje shows that on the national level, kraje use similar communication channels to cities; however, the kraje are better represented on key committees (see above) and working groups, allowing them to better communicate with the executive at the national level. On the other hand, on the EU level, cities benefited from personal contact with the executive president of CEMR and a vice-president of the European Parliament. In spite of the fact that at first sight the position of cities seemed less comfortable on the national level, this could be transformed into an advantage if we take into account that they could further benefit from a longer

12 On the other hand, kraje that see direct representation in Brussels as useful emphasized its importance for gaining information and contacts ('[the kraj's representation in Brussels] keeps its eyes open, gets involved, watches for chances for funding, deals with various activities in Brussels that occur, which could help or harm the kraje and especially South Moravia, gives presentations at those [...]') (Interview, South Moravia, 25 July 2014; comp. Sălăgeanu, 2014).

13 From the long-term perspective, this tactic also could have been seen as rather shortsighted, as it again connected to a great extent the effective promotion of the interests and positions of the cities with a particular person possessing both the experience and contacts on influential national and EU fora. This again only illustrates the limits of strategic behavior in an environment of limited financial and personal resources and in an atmosphere of a political culture that is not used to putting enough emphasis and importance on the communication between the substate and supranational level and the process of interests promotion via these channels. 
experience with interest advocacy. In other words, they were in the habit of being actors that had to firmly articulate their interests and in this process utilize a wider spectrum of contact points. Naturally, this is again not true for Czech cities en bloc. An important role is played by the municipalities themselves that take an active interest in EU legislation even at the preparation stage on the level of the relevant EU institutions, and not just when it is implemented into the Czech legal system. This means not only having the ability to prepare effective communication strategies with the relevant points on the national level (especially the UTMCR, or a ministry) and use of available channels at the supranational level, but also the availability of appropriate structures and (again) especially personnel in specific offices.

In the case of the new Member States, it is true that at the (not only) substate level, the development of a team, which ideally would have extensive experience from multiple levels of representation of local and regional interests (city/kraj, UTMCR/ ARCR, possibly ministerial positions, or even direct experience with EU institutions, particularly the Committee of the Regions), is a long-term project. ${ }^{14}$ The appropriate structures to deal with substate EU issues (especially in connection with the structural funds) were created in the context of EU accession, and have been understaffed, especially at the beginning. Effective work with European Union issues, which in addition to simply obtaining information also includes effective interest articulation of substate actors by means of various available channels on the national and supranational level, requires continuity of personnel; this is critical for the building of formal as well as informal contacts, which play also a vital role (especially) at the supranational level ('I think that in this area there are reserves. It won't do to leave out the horse-trading which took place after the last elections and still continues at the ministries. That's also not completely OK.' Interview, City Hall of Olomouc, 4 July 2014). It is also important to be aware of the importance of the EU issues from the side of the relevant players ('Unfortunately, other countries understand this reality better. If you want to promote some interest on the Union level, you also have to be a benefit for them. And that's not just true for the Council.' Interview, City Hall of Plzeň, 24 July 2014).

14 Interviews with representatives from cities as well as kraje stressed the importance of building internal structures and communications regarding the relevant institutions at the substate level ('[a] mechanism can be built well, but the problem might be communication in the context of an individual kraj and the Regional Authority. The ARCR can't control how information internally flows through the kraj. Each Hejtman [the elected leader of a kraj] gets the information, but the question is how it then gets transmitted to lower levels.' Interview, Association of Regions of the CR, 9 July 2014). The structural changes in the form of establishment of particular units or positions on the municipal and regional level were rather the outcome of top-down Europeanization in the polity dimension. Personnel discontinuity (and in some cases also insufficiency) has been another frequent limiting factor for building long-term contacts, which are necessary for effective lobbyist activity, especially on the EU level. 


\subsection{ITI as a divisive factor}

ITI has been divisive, escalating tensions between cities and kraje since the very beginning of the discussion about how to implement this instrument, around 2012. While kraje attempted to gain an advantage in new ROPs, which had yet not been promised to them for the following programming period, cities hoped to use ITI to strengthen the growth potential of major areas of agglomeration. Respondents generally agreed that from 2012 to January 2014 the kraje counted on them implementing ITI and altogether receiving several billion euros. The position of the kraje is understandable, insofar as they had become used to the idea that EU Regional Policy was something that had always been implemented at the level of regions up to that point (with a few exceptions), and that they could not imagine it being any other way. However, it soon became clear that the government was more inclined to the development of urban agglomerations. In particular, this inclination was confirmed by the 'Regional Development Strategy 2014-2020', a key strategic document regarding regional policy that emphasized urban development. The Strategy noted that ' $[\mathrm{i}] \mathrm{n}$ relation to urban issues, there is an increased role of cities in the system of implementation (e.g., delegating some tasks and responsibilities of the administration to cities, strengthening of partnerships and strategic planning, integrated approaches). The second level thus is increased emphasis on support of satisfying development needs at the subregional and local levels [...]. ITI will be a prominent implementation tool in the sections of development plans for metropolitan areas and the largest urban agglomerations' (Ministry of Regional Development of the Czech Republic, 2013, pp. 109-111). From this point on, major cities' hopes grew for ITI; nevertheless, kraje continuously tried to convince the government, and were far from losing hope in January 2014 during crucial negotiations among all actors.

Municipalities focused their strategy on another logical contact point - the European Commission - which is a key actor in the process of negotiating the form of implementation of regional policy. It is the Commission who signs the Partnership Agreement with the government of the Member State at the end of the process. Cities were personally assured that the Commission never considered that kraje would implement ITI, and repeated this stance during questioning by the UTMCR two months later. It was exactly at this point that the kraje undertook no meaningful activity at the EU level, and based on similar answers from key respondents, probably did not even know about the meetings with cities (based on the interviews, i.e., City Hall of Brno, 22 July 2014 or City Hall of Ostrava, 8 July 2014). It was at this time that the kraje likely suffered most from the lack of permanent representation in Brussels (in contrast to regions of many EU states who send representatives), as well as from their reluctance to think in terms of lobbying and multi-level governance.

This leads to the question of why at such a critical phase of the negotiations, the respective ministry stood up for the major cities and not the kraje. One partial explanation may lie in the political affiliation of the participating actors to which some respondents referred. While the majority of the principals of the kraje were members of 
the strongest government party, the ČSSD, since 2013 the key post of Minister of Regional Development has been in the hands of the second-strongest party, ANO (also in the government); ANO may have had a problem with allocating such an amount of financing to the kraje, which are controlled by their political rivals. Less 'conspiratorial' is the argument discussed above. Around 2012 or 2013, the government was already worried about the implementation of ROPs, as these were associated with an increase in corruption. Thus the goal was likely to exclude the kraje and the regional level as such from financial decision-making in regional policy. Therefore, from a certain point of view, the ITI can be seen as a 'welcomed' tool for the respective Czech Ministry of Regional Development to prevent the kraje from implementing the EU money. This clearly shows how the multiple opportunities the ITI offers can lead to possible conflict between old and new regions, especially in the specific context of EU Member States that had negative experiences with implementation of the EU funds as a result of corruption scandals. (We do not argue that this development is typical for the newer, post-communist EU member states, but the lack of experience and political culture do play a role here, and this should not be underestimated).

Since the Commission did not clearly say which actor should implement the money, national state administration shifted into that position and thus got a powerful tool. In this environment, the cities managed to find their way around and took advantage of the situation by turning to the supranational level channel, in spite of their initially less advantageous position in the negotiations and communication on the national level. Of course, the factor of internal political changes (as mentioned above) must also be taken into account if we want to fully understand the factors which may have influenced the governmental decision.

From the point of view of the current understanding of actors' interest articulation in the context of EU regional policy in the $\mathrm{CR}$, we find a relatively new image of mutual relations. Cities and kraje were faced with a situation in which they had the same goal, but only one of them could succeed. Obtaining the chance to implement ITI was strategic, particularly from the perspective of the substantial amount of money which could be budgeted to implement this tool in 2014-2020. Throughout the negotiating process various factors played a role as we described above. However, the strategy of cities focused on promoting their interests directly at the EU and the Commission respectively; this was a step that the kraje did not take at a crucial point. It could serve as an example of the importance of direct lobbying at the EU level, which not only the substate actors in the CR often have tended to underestimate.

\section{Conclusions}

Regionalization as a trend of the last two decades, particularly with the support of the European Commission, brings challenges to the concept of multi-level governance regarding precision. As more and more attention is paid to substate actors, it is increasingly important to differentiate among them. This is logical particularly when considering that the European Commission has shifted from its original emphasis on 
regional implementation of structural funds since 2000, and has increasingly looked at the metropolitan level, which is a degree 'lower' in MLG. As a result, it is increasingly appropriate to look at MLG as a four-level concept, dividing the local and regional levels from each other. Hand in hand with this process we now see a transformation in the character of governance structures, whereby the original 'substate actors' disintegrate into smaller basic units (cities, agglomerations) that have played ever larger roles in the context of European governance. This generally confirms the validity of Marks' definition from the beginning of the 1990s, which explicitly stressed the role of the local sphere in MLG.

We have demonstrated the splitting of these levels by their specific interests and preferences in the example of negotiations surrounding the implementation of the ITI regional policy tool in the Czech Republic. It turns out that in the discussion of this financial tool the Czech kraje and cities diverged significantly in their preferences. One key point in the entire process was the ability of cities to recognize their position in the MLG framework and their decision to bargain for a more advantageous position directly at the European Commission. Kraje, on the other hand, chose a conservative, more 'traditional' approach and their strategies, focused almost completely on the centralized authorities in Prague.

In the overall process, kraje made several fundamental mistakes. They:

A) underestimated the logic of negotiating on multiple levels and over-relied on working with the government. Further, they probably

B) underestimated the political nature of decision-making; at key points, the Ministry of Regional Development sided with cities or agglomerations led by major cities respectively. While kraje have mostly been headed by Social Democratic politicians, the relevant ministry was headed by their political rivals. While it is not possible to remodel history, it can be assumed that in the case of early establishment and maintenance of contact with the European Commission, the kraje could have prevented adverse developments. However, individual actors were not prepared; especially for the kraje, we see that at the beginning of their existence they did not learn the logic of multi-level governance. ${ }^{15}$

We conclude that the volatile situation between kraje and cities probably would not have occurred in the Czech Republic if the European Commission had not decided to support the so-called territorial dimension of regional policy in recent years. By doing so, whether consciously or unconsciously, the European Commission made special incentive structures (ITI in this case) in order to raise competitiveness and economic growth. The probably unintended consequence of this was conflict among regional and subregional actors. This can be demonstrated with the case of the CR,

15 On the other hand, it is also necessary to note the specific situation of the Czech Republic at the end of the 2007-2013 period, characterized by corruption scandals on the level of Regional Operational Programs; the government most likely wanted to prevent this in the future. 
where the conflict took place in the context of problems with the EU structural funds in the previous programming period and where the factor of the development of the internal political situation also played an important role. The outcome of the conflict then showed the importance of using multiple communication channels in the process of interest promotion of substate actors and may serve as one piece of evidence that multi-level communication should not be underestimated in these cases.

The major argument of this article may be used by further studies describing similar processes in other EU countries as well. The nature of conflict between new and old regions in different EU member states may depend on their tradition of cohesion policy, as well as on the longterm relations of their substate actors. The conflict potential, which was created by the new period 2014-2020, may gain various forms both in the older and the newer EU member states. Further research of this topic could bring other case studies, especially of the countries which share similar characteristics of the newer EU member states with the CR, representing the region of Central and Eastern Europe. These characteristics often include the lack of experience with 'multi-level' negotiations of the substate actors, frequently combined also with problems of political and administrative culture. Further research of the described processes both in the older and the newer EU member states may reveal the relative importance of these variables (or factors), which influence both the course and outcomes of the conflict (as we saw in the case of the $C R$ ).

\section{References:}

1. Bafarasat, A.Z., 'Exploring New Systems of Regionalism: An English Case Study', 2016, Cities, vol. 50, pp. 119-128.

2. Benedek, J. and Bajtalan, H., 'Recent Regionalization Discourses and Projects in Romania with Special Focus on the Szekélyland', 2015, Transylvanian Review of Administrative Sciences, no. 44E, pp. 23-41.

3. Benz, A., Politik in Mehrebenen-systemen, Wiesbaden: VS Verlag für Sozialwissenschaften, 2009.

4. Brno, 'Brno's annual budget', 2014, [Online] available at https://www.brno.cz/sprava-mesta/dokumenty-mesta/rozpocet/rozpocet-mesta-brna/souhrnny-rozpocet-statutarniho-mesta-brna-na-rok-2015/, accessed on March 13, 2016.

5. Burnham, P., Gilland Lutz, K., Grant, W. and Layton-Henry, Z., Research Methods in Politics, Houndmills: Palgrave Macmillan, 2008.

6. Deas, I. and Lord, A., 'From a New Regionalism to an Unusual Regionalism? The Emergence of Non-Standard Regional Spaces and Lessons for the Territorial Reorganisation of the State', 2006, Urban Studies, vol. 43, no. 10, pp. 1847-1877.

7. Callanan, M. and Tatham, M., 'Territorial Interest Representation in the European Union: Actors, Objectives and Strategies', 2014 Journal of European Public Policy, vol. 21, no. 2, pp. 188-210.

8. 'Czech Presidency of the European Union', 2009, [Online] available at www.eu2009.cz, accessed on April 1, 2016.

9. Dexter, L.A., 'Elite and Specialized Interviewing', Essex: ECPR, 2006. 
10. Dočkal, V. and Kozlová, M., 'Regionální politika v České republice' [Regional Policy in the Czech Republic], in Dočkal, V. (ed.), Regionální politika EU a naplňování principu partnerství. Př́padové studie České republiky, Německa a Slovinska [EU Regional Policy and the Implementation of the Principle of Partnership. Case Studies of the Czech Republic, Germany and Slovenia], Brno: IIPS, 2006, pp. 17-55.

11. European Commission, 'Integrated Territorial Investment', 2014, [Online] available at http://ec.europa.eu/regional_policy/sources/docgener/informat/2014/iti_en.pdf, accessed on February 4, 2016.

12. Harrison, J., 'From Competitive Regions to Competitive City-Regions: A New Orthodoxy, but Some Old Mistakes', 2007, Journal of Economic Geography, vol. 7, no. 3, pp. 311-332.

13. Havlík, V., Města jako partner v procesu vládnutí. Př́ipad českých a německých měst [Cities as a Partner in the Governance Process. The Case of Czech and German Cities], Brno: Muni Press, 2013.

14. Havlík, V., 'The EU Regional Policy in the Czech Republic and Its Impact on European Identification of Czech Citizen', in Tudela Arada, J. and Kölling, M. (eds.), EU Regional Policy and the Identification with Europe, Zaragoza: Cuadernos Manuel Giménez Abad, 2015, pp. 15-23.

15. Heinelt, H. and Lang, A., 'Regional Actor Constellations in EU Cohesion Policy: Differentiation along the Policy Cycle', 2011, Central European Journal of Public Policy, vol. 5, no. 2, pp. 4-28.

16. Hradec Králové, 'Integrované územní investice (ITI)' [Integrated Territorial Investment (ITI)], 2014, [Online] available at http://www.hradeckralove.org/urad/integrovane-uzemni-investice-iti, accessed on February 7, 2016.

17. Jeffery, C., 'Sub-National Mobilization and European Integration: Does It Make Any Difference', 2000, Journal of Common Market Studies, vol. 38, no. 1, pp. 1-23.

18. Kassim, H., 'The Europeanization of Member State Institutions', in Bulmer, S. and Lequesne, C. (eds.), The Member States of the European Union, Oxford: Oxford University Press, 2005, pp. 285-316.

19. Littig, B., 'Interviewing the Elite - Interviewing Experts: Is There a Difference?', in Bogner, A., Littig, B. and Menz, W. (eds.), Interviewing Experts, London: Palgrave Macmillan, 2009, pp. 98-113.

20. Marks, G., 'Structural Policy and Multilevel Governance in the EC', in Cafruny, A.W. and Rosenthal, G.G. (eds.), The State of the European Community, New York: Lynne Rienner, 1993, pp. 391-410.

21. Ministry of Regional Development of the Czech Republic, 'Strategie regionálního rozvoje ČR 2014-2020' [Regional Development Strategy of the Czech Republic 2014-2020], Prague: Ministerstvo pro místní rozvoj, 2013.

22. Marks, G. and Hooghe, L., 'Contrasting Visions of Multi-level Governance', in Bache, I. and Flinders, M. (eds.), Multi-level Governance, New York: Oxford University Press, 2005, pp. 15-30.

23. Münch, C., Emanzipation der lokalen Ebene? Kommunen auf dem Weg nach Europa, Wiesbaden: VS Verlag für Sozialwissenschaften, 2006.

24. South Moravia, 'South Moravia's annual budget', 2014, [Online] available at http://www. kr-jihomoravsky.cz/Default.aspx?ID=246473\&TypeID=2, accessed on March 4, 2016. 
25. Sălăgeanu, R., 'Creating European Policy from a Regional Perspective - The Innovation of Transition Regions within the Regional Policy of the EU. Evidence from Saxony-Anhalt', 2014, Politologický časopis - Czech Journal of Political Sciencevol, vol. XXI, no. 2, pp. 131-150.

26. Soldatos, P. and Michelmann, H.J., 'Subnational Units' Paradiplomacy in the Context of European Integration', 1992, Journal of European Integration, vol. 15, no. 2-3, pp. 129134.

27. Zimmermann, K., 'Cities for Growth, Jobs and Cohesion. Die implizite Stadtpolitik der EU', in Heinelt, H. and Vetter, A. (eds.), Lokale Politikforschung heute, Wiesbaden: VS Verlag für Sozialwissenschaften, 2008, pp. 79-102.

28. Zimmermann, K. and Heinelt, H., Metropolitan Governance in Deutschland. Regieren in Ballungsräumen und neue Formen politischer Steuerung, Wiesbaden: Springer VS, 2012.

\section{Interviews:}

1. Association of Regions of the Czech Republic, 9.12.2014.

2. Association of Towns and Municipalities of the Czech Republic, 15.12.2014.

3. Association of Towns and Municipalities of the Czech Republic, 28.11.2014.

4. City of Brno, 11.03.2015.

5. City of Brno, 22.07.2014.

6. City of Havírov, 4.08.2014.

7. City of Olomouc, 4.07.2014.

8. City of Ostrava, 8.07.2014.

9. City of Plzeň, 24.07.2014.

10. City of Plzeň, 5.09.2014.

11. City of Prague, 12.08.2014.

12. City of Prague, 9.07.2014.

13. Kraj Carlsbad, 10.09.2014.

14. Kraj Hradec Králové, 11.09.2014.

15. Kraj Moravia-Silesia, 8.07.2014.

16. Kraj South Moravia, 25.07.2014.

17. Ministry of Regional Development, 2.09.2014. 